\title{
Antibiogram Study for Some Microbial Isolates from Al-Khoms Teaching Hospital, Libya
}

\author{
Bioprabhu sangar ${ }^{1}$, Soad Imhmed R.Alkhumsi ${ }^{2}$, Younis Alzaidi ${ }^{3}$, \\ Salem Edrah ${ }^{4}$, Salem Ali Ibrahim ${ }^{5}$, Atiya Hebishe ${ }^{2}$
}

1. Dept of Microbiology, Faculty of Medicine, El-mergib university, Al-khoms, Libya.

2. Dept of Medicine, Faculty of Medicine, El-mergib university, Al-khoms, Libya.

3. Department of Biology, Faculty of Education, El-Mergib University, Al-khoms, Libya.

4. Dept of Chemistry, Faculty of Sciences, El-mergib university, Al-khoms, Libya.

5. Health science faculty, El-mergib university, Al-khoms, Libya.

\begin{abstract}
Antimicrobial Resistant (AMR) is rapidly increasing across the globe. This increasing number of reports on continued emergence of resistance to antimicrobial drugs makes the physicians to know periodic monitoring of the emergence of resistance in the microorganisms in their local area. Development of resistance is not only in bacteria and also in some fungus.

This study was conducted at the Central laboratory of Medical Microbiology, Al-khoms teaching hospital, AlKhoms, Libya. Bacteria and fungi were isolated from the samples arrived to the laboratory. Frequently isolated bacteria and fungi were taken for this study.

Antibacterial susceptibility test was carried out in Mueller hinton agar and antifungal activity study was done with Sabouraud dextrose agar. The antimicrobial drugs were selected based on the availability and prescription frequency of these drugs in the study area.

Combination of Amoxicillin and Clavulonic acid (Augumentine) shows highest antibacterial effect on most of the studied bacteria. In fungal study, Euconazole has more antifungal effect on both Candida albicans and Aspergillus niger.
\end{abstract}

Keywords: Antibiogram, Al-khoms teaching hospital, Libya,

\section{Introduction}

Antimicrobial agents have been the only easily and widely used therapeutic option available to counter the infections caused by diverse microbial agents. However, microbial populations have developed various strategies to overcome these antimicrobial agents - a major contributing factor in the development of antimicrobial resistance world-wide.

Consumption of antimicrobials is rising in Sub-Sahara Africa (Lakshminarayan, 2006). Very little is known about current resistance patterns of common pathogenic bacteria in Sub-Saharan Africa where surveillance capacity is minimal (Okeke et al., 2007). In Sub-Saharan Africa, the relative burden of infectious diseases is high (Murray et al., 2012). However, often only a small repertoire of (poor-quality) antimicrobials is available, which may be sold over the counter without proper diagnostic guidance. Inadequate hygiene and infection control in hospitals may increase the spread of (multi)drug-resistant pathogens (Morgan et al., 2011).

There is also a need for accurate, reproducible and predictive susceptibility testing of fungal isolates in order to help to inform clinical choice. Some types of Candida are becoming increasingly resistant to first-line and second-line antifungal medications, namely, fluconazole and echinocandins (anidulafungin, caspofungin, and micafungin) (Lockhart et al., 2012). Although most antifungal resistance occurs in Candida species, resistance in other types of fungi, such as Aspergillus, is also an emerging issue. The full extent of the problem is still unknown, but the global prevalence of azole resistance in Aspergillus is estimated to be approximately 3 to 6 percent (Arendrup, 2014).

Effective empirical therapy of bacterial and fungal diseases requires knowledge of local antimicrobial resistance (AMR) and antifungal resistance (AFR) patterns, acquired through up-to-date surveillance. The selections of relevant antibiotics were broadened based on expert opinion, frequently prescribed by the physician and included narrow-spectrum and extended-spectrum.

Although antibiotic-resistant bacterial infections are a widely-recognized public health threat, less is known about the effects of antifungal resistance and the burden of drug-resistant fungal infections. This highlights the need for an improved understanding of the reasons for their emergence, heightened awareness among medical and public health communities about these infections, and greater attention to methods that can be used to prevent and control them. 


\section{Samples and area of study:}

\section{Materials And Methods}

This study was conducted at the Central laboratory of Medical Microbiology, Al-khoms teaching hospital, Al-Khoms, Libya. Bacteria and fungi were isolated from the samples arrived to the laboratory. Frequently isolated bacteria and fungi were taken for this study.

\section{Antimicrobial susceptibility testing (AMST):}

Susceptibility testing was performed by Kirby-Bauer disk diffusion technique according to criteria set by CLSI (2011). The inoculums was prepared by picking parts of similar test organisms with a sterile wire loop and suspended in $1 \mathrm{ml}$ of sterile normal saline. Two colonies were picked and mixed in the saline in order to maintain the uniform inoculums. The test organism was uniformly seeded over the Mueller-Hinton agar (oxoid, UK) surface and exposed to a concentration gradient of antibiotic diffusing from antibiotic-impregnated paper disk into the agar medium, and then incubated at $37^{\circ} \mathrm{C}$ for $24-48$ hours. Diameters of the zone of inhibition around the discs were measured to the nearest millimeter using a ruler.

Antifungal test was carried out in Sabouraud Dextrose agar (Oxoid, UK). Inoculums preparation and inoculation on the media as same manner of antibacterial susceptibility test. Antifungal test plates were inoculated at $25^{\circ} \mathrm{C}$ for $5-7$ days.

The drugs tested for both gram negative and gram positive bacteria and single celled (Candida) and mold (Aspergillus) are reported in table 1 (Bioanalyse, Turkey). These antimicrobial selected based on the availability and prescription frequency of these drugs in the study area.

\section{Results And Discussion}

Table 1. List of antibiotics used for the antibiotic sensitivity testing.

\begin{tabular}{|c|c|c|c|}
\hline No & Antibiotics & code & Disc potency \\
\hline \multicolumn{4}{|c|}{ A. Antibacterial: } \\
\hline 1 & Ampicillin & AMP10 & $10 \mu \mathrm{g}$ \\
\hline 2 & Amoxicillin \& Clavulanic acid (Augumentin) & AMC30 & $10 \mu \mathrm{g}$ \\
\hline 3 & Cefadroxil & CFR30 & $30 \mu \mathrm{g}$ \\
\hline 4 & Chloramphenicol & $\mathrm{C} 30$ & $30 \mu \mathrm{g}$ \\
\hline 5 & Gentamycin & CN10 & $10 \mu \mathrm{g}$ \\
\hline 6 & Nalidixic acid & NA30 & $30 \mu \mathrm{g}$ \\
\hline 7 & Penicillin G & P10 & $10 \mathrm{U}$ \\
\hline 8 & Vancomycin & VA5 & $5 \mu \mathrm{g}$ \\
\hline \multicolumn{4}{|c|}{ B. Antifungal: } \\
\hline 1 & Euconazole & ECO10 & $10 \mu \mathrm{g}$ \\
\hline 2 & Flucanozole & FLU25 & $25 \mu \mathrm{g}$ \\
\hline 3 & Miconazole & MCZ10 & $10 \mu \mathrm{g}$ \\
\hline
\end{tabular}

(All drugs were purchased from Bioanalyse, Turkey)

Table 2: Antibiotic sensitivity test for bacterial isolates in Al-khoms teaching hospital.

\begin{tabular}{|l|l|c|c|c|c|c|c|c|c|}
\hline S. No. & \multirow{2}{*}{ Bacteria } & \multicolumn{7}{|c|}{ Antibiotics (Zone of inhibition in mm) } \\
\cline { 3 - 10 } & & Ampicillin & Augumentin & Cefedox & $\begin{array}{l}\text { Chloram } \\
\text { phenicol }\end{array}$ & $\begin{array}{l}\text { Genta } \\
\text { mycin }\end{array}$ & $\begin{array}{l}\text { Nalidixic } \\
\text { acid }\end{array}$ & Penicillin & $\begin{array}{l}\text { Vanco } \\
\text { Mycin }\end{array}$ \\
\hline 1 & E. coli & 13 & 48 & 00 & 28 & 07 & 00 & 00 & 23 \\
\hline 2 & $\begin{array}{l}\text { K. } \\
\text { pneumoniae }\end{array}$ & 00 & 18 & 00 & 26 & 16 & 22 & 00 & 00 \\
\hline 3 & $\begin{array}{l}\text { P. } \\
\text { auruginosae }\end{array}$ & 00 & 00 & 00 & 00 & 13 & 00 & 00 & 00 \\
\hline 4 & Staph. aureus & 00 & 20 & 00 & 20 & 22 & 20 & 10 & 17 \\
\hline
\end{tabular}

Photo1: Staphylococcus aureus

Photo2: Klebsiella pneumonia 

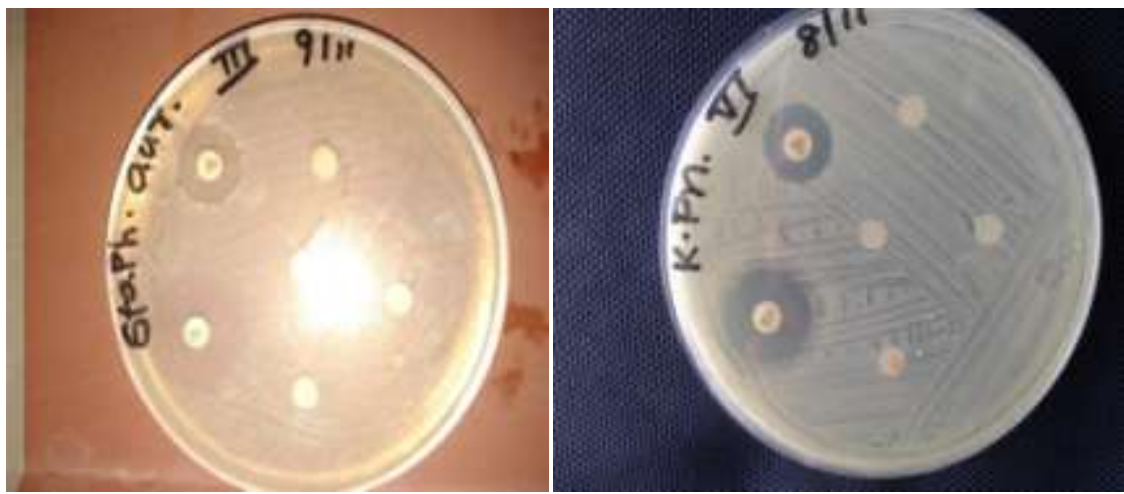

Table 3: Antifungal test of isolates from Al-khoms teaching hospital.

\begin{tabular}{|l|c|c|c|c|}
\hline S. No. & \multirow{2}{*}{ Fungus } & \multicolumn{3}{|c|}{ Antifungus (Zone of inhibition in mm) } \\
\cline { 3 - 5 } & & Econazole & Fluconazole & Miconazole \\
\hline 1 & Aspergillus niger & 34 & 18 & 10 \\
\hline 2 & Candida albicans & 20 & 13 & 00 \\
\hline
\end{tabular}

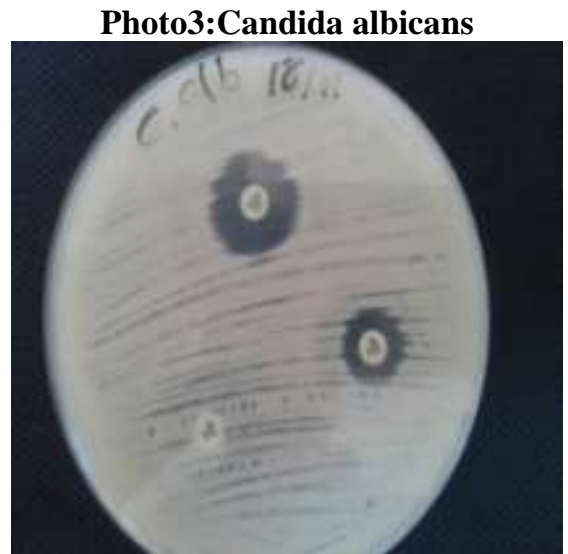

\section{Photo4:Aspergillus niger}

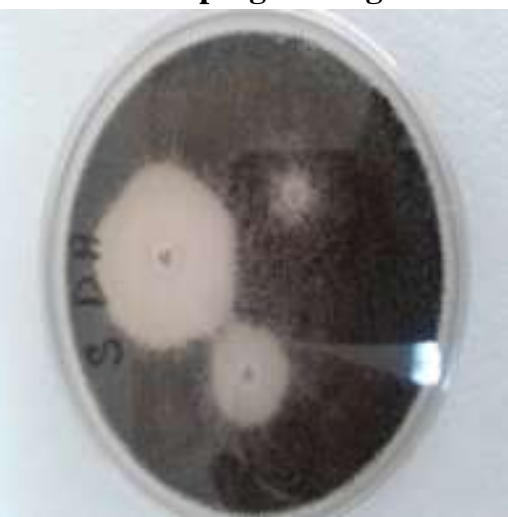

Resistance to the selected antimicrobials was very high. Combination of Amoxicillin and Clavulonic acid shows highest antibacterial effect on most of the studied bacteria (Table 2 and Phot 1 and 2). E.coli showed resistant to all drugs used except Augumentin, Gentamycin and Vancomycin. This is consistent with other study (Ayoade, 2014). The average resistance of the isolates to all the antibiotics of gram positive cocci (Staphylococcus aureus) was higher than the gram negative bacilli (E.coli, Kl.pneumoniae and Pseudomonas auruginosae). This is similar to the study done in Ethiopia with average resistance of gram positive cocci isolates and gram negative bacilli isolates (Mulu et al., 2012). The overall multiple drug resistance (two and above antimicrobial classes) of the isolates in this study was more which was in line with previous study done in different parts of the world (Bayram et al., 2013). High resistance of the isolates to antibiotics may be due to practicing self medication, lack of diagnostic laboratory services or unavailability of guideline regarding the selection of drugs thereby which lead to inappropriate use of antibiotics.

In this study, Euconazole has more antifungal effect on both Candida albicans and Aspergillus niger (Table 3 and Photo 3 and 4). Fluconazole has little effect on Aspergillus niger but no effect on Candida albicans. Likewise, Miconazole has little effect on candida albicans but no effect on Aspergillus niger. As with Candida and Aspergillus infections are associated with high mortality, and resistant infections can develop in people who've had previous exposure to certain antifungal medications (Howard et al.,2009). In addition, some studies suggest that resistance in Aspergillus may be partially driven by the use of agricultural azoles, which protect crops from fungi (Verweij et al., 2009). More research is needed about the mechanisms of resistance in Aspergillus and the prevention of resistant Aspergillus infections.

\section{Conclusion}

Augumentine has high antibacterial effect on most of the studied bacteria followed by Gentamycin. In fungal isolates, Euconazole has better effect on both the fungi. Currently prescribed antibiotics without proper test are critical. Clear study on the efficacy of an antibiotic with minimised resistant or sensitive may reduce the risk of AMR in this millennium. So, novel approaches to AMR surveillance are needed, which may depend on smaller sample sizes, regular monitoring and can provide locally relevant knowledge of AMR patterns and allowing for appropriate empirical antimicrobial therapy. This would help and guide the physicians in 
prescribing the right combinations of anti-microbials to limit and prevent the emergence of antibiotic resistant microorganisms.

\section{References}

[1]. Arendrup MC (2014) Update on antifungal resistance in Aspergillus and Candida. Clinical microbiology and infection 6:42-48.

[2]. Ayoade E, Moro DD and Ebene OL (2014) Prevalance and antimicrobial susceptibility pattern of asymptomatic urinary tract infections of bacterial and parasitic origins among university students in redemtion camps, Ogun state, Nigeria. Open J. Of Med. Microbiology 3:219-226.

[3]. Bayram Y, Parlak M, Aypak C and Bayram İ (2013)Three-year review of bacteriological profile and anti-biogram of burn wound isolates in Van, Turkey. Int $\mathrm{J}$ Med Sci.10(1):19-23

[4]. Clinical and Laboratory Standards Institute (CLSI) (2011) Performance standards for antimicrobial susceptibility testing; Eighteenth Informational supplement. CLSI document M100S18. Wayne PA: Clinical and Laboratory Standards Institute.

[5]. Howard SJ, Cerar D and Anderson MJ (2009) Frequency and evolution of Azole resistance in Aspergillus fumigatus associated with treatment failure. Emerging infectious diseases 15:1068-1076.

[6]. Laxminarayan R, Bhutta Z and Duse A (2006) Drug resistance. In: Jamison DT, Breman JG, Measham AR, editors. Disease Control Priorities in Developing Countries. 2nd edn. Washington, DC: World Bank.

[7]. Lockhart SR, Iqbal N and Cleveland AA (2012)Species identification and antifungal susceptibility testing of Candida bloodstream isolates from population-based surveillance studies in two U.S. cities from 2008 to 2011. Journal of clinical microbiology 50:34353442 .

[8]. Morgan DJ, Okeke IN and Laxminarayan R (2011) Non-prescription antimicrobial use worldwide: a systematic review. Lancet Infect Dis. 11:692-701.

[9]. Mulu W, Kibru G, Beyene G and Damtie M (2012) Postoperative nosocomial infections and antimicrobial resistance pattern of bacteria isolates among patients admitted at Felege Hiwot Referral Hospital, Bahirdar. Ethiopia Ethiop J Health Sci,22(1):718.

[10]. Murray CJ, Ezzati M and Flaxman AD (2012) GBD 2010: a multi-investigator collaboration for global comparative descriptive epidemiology. Lancet Infect Dis.380:2055-2058.

[11]. Okeke IN, Aboderin OA and Byarugaba DK (2007) Growing problem of multidrug-resistant enteric pathogens in Africa. Emerg Infect Dis. 13:1640-1646.

[12]. Verweij PE, Snelders E, Kema GH, Mellado E and Melchers WJ (2009) Azole resistance in Aspergillus fumigatus: a side-effect of environmental fungicide use? Lancet Infect Dis.9:789-795. 